\title{
Applying Feasibility Investigation of Resin Modifying Agent in Asphalt Pavement Materials
}

\author{
Lijing Chu, ${ }^{1,2}$ Yi Li, ${ }^{3}$ Linghui Huang, ${ }^{4}$ Jingyu Qiu, ${ }^{5}$ Xiaolong Sun ${ }^{D},{ }^{5}$ Zhi Cang, \\ and Jianbing $\mathbf{L v}^{5}$ \\ ${ }^{1}$ Guangzhou Urban Planning \& Design Survey Research Institute, Guangzhou 510060, China \\ ${ }^{2}$ Guangdong Enterprise Key Laboratory for Urban Sensing, Monitoring and Early Warning, Guangzhou 510060, China \\ ${ }^{3}$ Guangzhou North Second Ring Transport Technology Co., Ltd., Guangzhou 510000, China \\ ${ }^{4}$ Guangdong Nanyue Transportation InvestmentङConstruction Co., Ltd., Guangzhou 510623, China \\ ${ }^{5}$ School of Civil and Transportation Engineering, Guangdong University of Technology, Guangzhou 510006, China \\ ${ }^{6}$ Datongbei Expressway Management Co., Ltd., Shanxi Transportation Holding Group Co., Ltd., Taiyuan 030006, China
}

Correspondence should be addressed to Xiaolong Sun; xls1998@gdut.edu.cn

Received 6 October 2021; Accepted 22 November 2021; Published 3 December 2021

Academic Editor: Jiupeng Zhang

Copyright (c) 2021 Lijing Chu et al. This is an open access article distributed under the Creative Commons Attribution License, which permits unrestricted use, distribution, and reproduction in any medium, provided the original work is properly cited.

In order to promote the resin modifying agent applied into pavement materials, a type of resin modifying agent was selected as the modifier to prepare modified asphalt. The molecular crystal structure of the modifying material was characterized by using the $\mathrm{X}$-ray diffraction test (XRD). The microstructure and element composition of PA6 was investigated through focused ion beam scanning electron microscopy (FIB-SEM). The thermal property and functional groups of PA6 were studied by thermogravimetric analysis-Fourier infrared spectroscopy (TG-FTIR) test. The physical property and rheological properties of PA modified asphalt were evaluated to confirm the applying feasibility of PA6 in asphalt. The results indicated that PA6 was the semicrystalline polymer and the existence of $\gamma$ crystal form might improve the toughness of asphalt materials effectively. The thermal decomposition process of PA6 could be divided into three stages roughly: inert weight loss stage, rapid weight loss stage, and stable stage. The amount of PA6 modifier should be appropriately controlled during the application process to ensure the comprehensive effect of PA6 on high-temperature performance and low-temperature performance. The corresponding initial modulus attenuation value of PA modified asphalt was less than 70\# asphalt under the same test conditions.

\section{Introduction}

Polymer modified asphalt mainly includes thermoplastic elastomers, resins, and rubbers [1]. Among them, polymermodified asphalt has been used widely due to its good technical and economic advantages [2,3]. Various polymermodified asphalts have been extensively studied worldwide. There are many types of polymers used to modify asphalt, which are divided into three categories generally: rubber, such as natural rubber, styrene butadiene rubber, chloroprene rubber, and butadiene Rubber; thermoplastic elastomers, such as polystyrene-b-polybutadiene-b-polystyrene and polystyrene-b-polyisoprene-b-polystyrene; resins: thermoplastic resins, such as polyethylene, ethylene-vinyl acetate copolymer, and polyamide; thermosetting resins such as epoxy resin [4-6]. Different modifiers have their own inherent characteristics. Through research and application, the variety and quantity of modifiers used are also constantly changing. In many inland areas of our country, the summer is hot and the winter is cold, and the high- and low-temperature performance requirements of the modified asphalt are relatively high $[7,8]$. In the application engineering of modified asphalt, resin-based modified asphalt is more and more favored because it can take both aspects into consideration [9-11]. In recent years, as the good asphalt modification material, resin modifiers could not only improve the various road performances of asphalt binders significantly but also have the significant improving effect on 
the anti-ultraviolet aging performance of asphalt materials [12-15]. However, since the improving mechanism and effect of resin modifiers are still unclear, the application of resin in asphalt material is limited.

In this work, a type of resin modifying agent was selected as the modifier to prepare modified asphalt. The molecular crystal structure of the modifying material was characterized by using the X-ray diffraction test (XRD). The microstructure and element composition of PA6 was investigated through focused ion beam scanning electron microscopy (FIB-SEM). The thermal property and functional groups of PA6 were studied by TG-FTIR test. The physical property and rheological properties of PA-modified asphalt were evaluated to confirm the applying feasibility of PA6 in asphalt.

\section{Materials and Methodology}

\subsection{Materials}

2.1.1. Asphalt. 70\# asphalt was chosen in this study and its technical properties were presented in Table 1.

2.1.2. PA Modifier. PA6 was selected as the asphalt modifying agent for preparing polymer-modified asphalt and the dosage of polymer-modified asphalt was $0.2 \%$ of asphalt weight. The properties of the selected PA modifier were shown in Table 2.

2.2. Preparation Process of PA-Modified Asphalt. 70\# asphalt was put in the oven at $110^{\circ} \mathrm{C}$ and kept for $6 \mathrm{~h}$. The
TABLE 1: Technical properties of 70\# asphalt.

\begin{tabular}{|c|c|c|c|}
\hline \multicolumn{2}{|c|}{ Technical indices (SK70\# asphalt) } & Value & Specification \\
\hline \multicolumn{2}{|c|}{ Softening point $/{ }^{\circ} \mathrm{C}$} & 49.2 & $>43$ \\
\hline \multicolumn{2}{|c|}{ Penetration $\left(25^{\circ} \mathrm{C}, 100 \mathrm{~g}, 5 \mathrm{~s}\right) / 0.1 \mathrm{~mm}$} & 70.3 & $60 \sim 80$ \\
\hline \multicolumn{2}{|c|}{ Ductility $\left(10^{\circ} \mathrm{C}\right) / \mathrm{cm}$} & 26.5 & $>15$ \\
\hline \multicolumn{2}{|c|}{ Brookfield viscosity $\left(135^{\circ} \mathrm{C}\right) / \mathrm{mPa} \cdot \mathrm{s}$} & 504 & - \\
\hline \multirow{3}{*}{$\begin{array}{l}\text { Thin film oven } \\
\text { test }\end{array}$} & $\begin{array}{c}\text { Residual penetration ratio } \\
(\%)\end{array}$ & 59.03 & $\geq 54$ \\
\hline & $\begin{array}{l}\text { Softening point increment } \\
\left({ }^{\circ} \mathrm{C}\right)\end{array}$ & 5.7 & - \\
\hline & Residual ductility (cm) & 7.4 & $\geq 4$ \\
\hline
\end{tabular}

temperature of the asphalt container with asphalt was kept at $130^{\circ} \mathrm{C}$. The amount of PA was weighed and added into asphalt. In the process of adding, the stirring was kept performing to promote the mixing between asphalt and PA. Finally, the prepared PA-modified asphalt was stirred at $600 \mathrm{rad} / \mathrm{min}$ for 8 minutes and the preparation of modified asphalt was completed.

\subsection{Methodology}

2.3.1. XRD Test. X-ray diffraction test (XRD) was performed by the D8 ADVANCE X-ray diffractometer produced by German Bruker to characterize the molecular crystal structure of the material. The scanning angle range ranged from $1.5^{\circ} \sim 60^{\circ}$. The scanning rate was $5^{\circ} / \mathrm{min}$ and the step size of $0.02^{\circ}$. The calculation method of the test index is shown as follows:

Crystallinity calculation formula:

$$
\text { Crystallinity }=\frac{\text { Area of crystalline peaks }}{\text { Area of all peaks (crystalline }+ \text { Amorphous) }} \times 100 \% \text {. }
$$

Scherer formula for calculating the grain size:

$$
D=\frac{K \gamma}{B \cos \theta}
$$

where $\mathrm{D}$ is the average thickness of the crystal grain perpendicular to the crystal plane, $\mathrm{K}$ is Scherrer constant, $\gamma$ is $\mathrm{X}$-ray wavelength, $\mathrm{B}$ is the half-height width or integral width of the measured sample diffraction peak, and $\Theta$ is the Bragg angle.

2.3.2. SEM-EDS Analysis. The focused ion beam scanning electron microscopy (FIB-SEM) was used to investigate the microstructure of the PA6 modifier. The magnification of the SEM test was 2000 times, 5000 times, and 10000 times. The element mapping by EDS analysis was performed on the main elements of PA6.

2.3.3. TG-FTIR Analysis. The thermal property and molecular structure were investigated by fast speed thermogravimetric analyzer (TGA/DSC + Nicolet IS50, USA) coupled with FTIR spectrometer (Mettler Toledo Thermofisher, USA). The heating temperature was from $20^{\circ} \mathrm{C}$ to $600^{\circ} \mathrm{C}$ and the heating rate was $10^{\circ} \mathrm{C} / \mathrm{min}$ in the nitrogen flow of $100 \mathrm{~mL} / \mathrm{min}$.

2.3.4. Physical Property. Softening point, penetration, and ductility tests were performed to evaluate the modifying effect of PA6 on the physical properties of asphalt binder. The physical tests were conducted according to the specification of ASTM D36[22], ASTM D5[23], and ASTM D113 [24].

2.3.5. Rheological Properties. The testing temperature of Brookfield viscosity were $90^{\circ} \mathrm{C}, 135^{\circ} \mathrm{C}$, and $175^{\circ} \mathrm{C}$, and the test was performed according to T0625-2011. Linear amplitude sweep test (LAS) was carried out to evaluate the fatigue characteristics of PA-modified asphalt. The test temperature was $18^{\circ} \mathrm{C}$ and $8 \mathrm{~mm}$ flat plate was selected, of which the spacing was $1 \mathrm{~mm}$. Firstly, the specimen was preloaded for 100 cycles (10 s) at the strain of $0.1 \%$. Then, the 
TABLE 2: Technical properties of PA6.

\begin{tabular}{llllll}
\hline Modifier & Density $\left(\mathrm{g} \cdot \mathrm{cm}^{-3}\right)$ & Melting point $\left({ }^{\circ} \mathrm{C}\right)$ & Decomposition temperature $\left({ }^{\circ} \mathrm{C}\right)$ & Tensile strength $(\mathrm{Mpa})$ & Bending strength (Mpa) \\
\hline
\end{tabular}

load was continuously performed with the linear growth rate of $1 \%$ in the strain level from $1 \%$ to $30 \%$. Each strain level was loaded for 100 cycles $(10 \mathrm{~s})$ and the total testing time was 310 s.

\section{Results and Discussion}

\subsection{Characteristics and Applying Feasibility of PA-Modifying Agent}

3.1.1. XRD Analysis. As shown in Figure 1, the characteristic peaks of PA6 mainly appeared at $20.2^{\circ}$ and $23.8^{\circ}$, which indicated that PA6 was mainly the typical $\alpha$ crystal structure. Although there were three crystalline forms of PA6, only the crystalline form of the $\alpha$-monoclinic system could be obtained through test results at room temperature. The diffraction peak of $\gamma$ crystal form was about $21.03^{\circ} \sim 22.8^{\circ}$ in Figure 1 and the peak intensity was low, which supposed that the structure of PA6 was still dominated by $\alpha$ crystal form companied with a small amount of $\gamma$ crystal form. Under the condition of $\alpha$ crystal form as the dominant condition, the crystallinity of PA6 could be obtained by the crystallinity calculation formula to be $67.7 \%$, which suggested that PA6 was the semicrystalline polymer and the existence of $\gamma$ crystal form might improve the toughness of asphalt materials effectively.

3.1.2. SEM-EDS Analysis. It could be observed from Figure 2 that the sizes of the PA6 particle structure were similar, showing the crystal morphology, and the structure had obvious angularity. The radial size of PA6 particles was about $50 \mu \mathrm{m}$, while the vertical size was about $25 \mu \mathrm{m}$. The particle structure was mainly elongated and flat. The prismatic shape of the grain structure was the most prominent at both ends and the structure boundary was clear. The particle structure was enlarged to 5000 times (Figure 2(b)), and it could be seen that the crystal structure of the particle surface is obvious and the surface presents the layered distribution. Through further magnification to 10,000 times (Figure 2(c)), it was found that the surface of the layered structure was relatively smooth and only the edges were connected to the surface by strips of material. In addition, there were a small number of pits. The element mapping results in Figures 2(e) and 2(f) reflected the distribution of the two main elements in PA6. The results showed that $\mathrm{C}$ and $\mathrm{O}$ were the main constituent elements of PA6 and the contents of the two typical elements were 78.55\% and $15.10 \%$, respectively, whose total content exceeded $90 \%$. Figure 2(d)-2(f) also confirmed that $\mathrm{C}$ and $\mathrm{O}$ were the main constituent elements of PA6, and besides, also containing certain miscellaneous elements.

3.1.3. TG Analysis. According to the analysis in Figure 3, the thermal decomposition process of PA6 could be divided into three stages roughly: inert weight loss stage, rapid weight loss

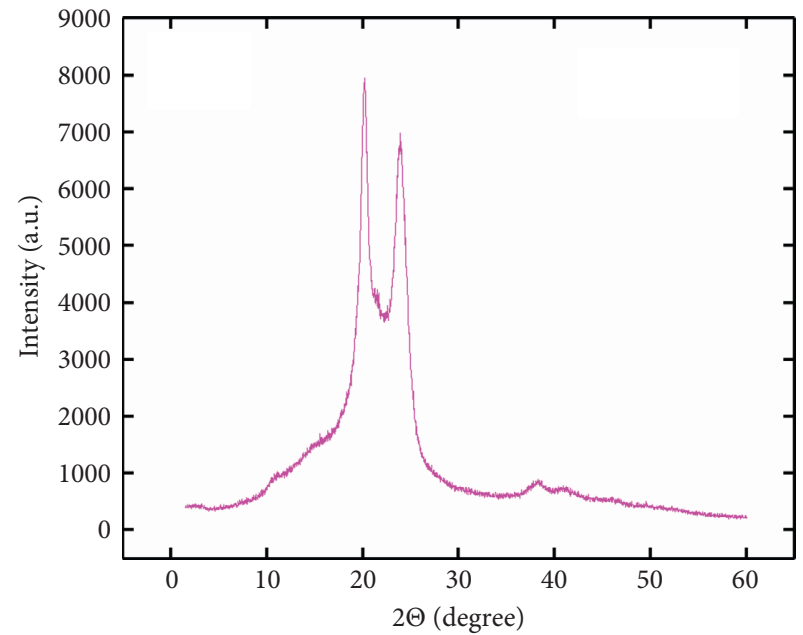

FIgURE 1: XRD testing results of the PA6 modifier.

stage, and stable stage. In the inert weight-loss stage, the short-term slight mass loss happened at the beginning of the temperature change. The residual mass was about $98.61 \%$ of the total mass, and the mass loss was $1.39 \%$. This mass loss continued to $265^{\circ} \mathrm{C}$, which might be due to the fact that PA6 powder absorbed water easily and the water evaporated when the temperature rose. As the temperature continued to rise, it entered the stage of rapid weight loss $\left(265^{\circ} \mathrm{C} \sim 492^{\circ} \mathrm{C}\right)$. The thermal decomposition rate of PA6 was accelerated. The analysis of the DTG curve (Figure 3(b)) showed that the maximum decomposition peak appeared at $454^{\circ} \mathrm{C}$. The corresponding TG curve slope changed significantly and the maximum weight loss rate in this range reached $97.6 \%$. The stable stage ranged from $492^{\circ} \mathrm{C}$ to $500^{\circ} \mathrm{C}$, and the TG curve changed relatively smoothly, which indicated that the PA was basically in the constant weight state after thermal weight loss, and the residual mass ratio was about $1.01 \%$.

3.1.4. Dynamic FTIR Analysis. It could be seen from Figures 4 and 5 that the change of intensity curve of PA6 started to be detected from about 37 minutes. In the infrared spectrum corresponding to $1700 \mathrm{~cm}^{-1}$ and $2400 \mathrm{~cm}^{-1}$, small and sharp stretching peaks appeared and the peak intensity curve reached the maximum at about $42 \mathrm{~min}$. Absorption peaks of lower intensity appeared in the range of 3400 to $3500 \mathrm{~cm}^{-1}$, which might be caused by the $\mathrm{N}-\mathrm{H}$ stretching vibration. The strong peak at $1665.33 \mathrm{~cm}^{-1}$ might be the amide I band $(\mathrm{C}=\mathrm{O})$. At $2937.03 \mathrm{~cm}^{-1}$, the high-intensity characteristic peak appeared along with the medium-intensity methylene characteristic peak. The characteristic peak of $\mathrm{C}=\mathrm{O}$ bond stretching vibration of the carboxyl group appeared at the wavenumber of $1707.52 \mathrm{~cm}^{-1}$. When the time reached $49.71 \mathrm{~min}$, the 


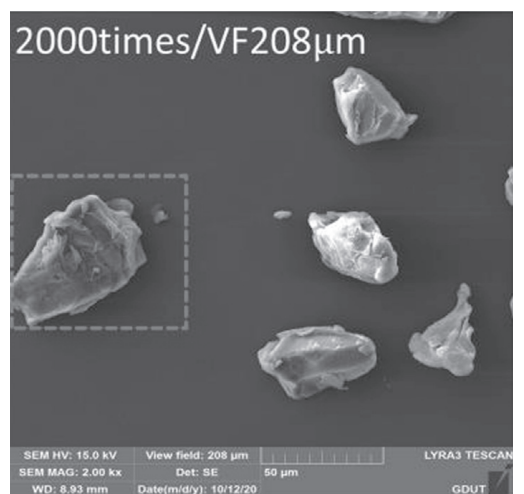

(a)

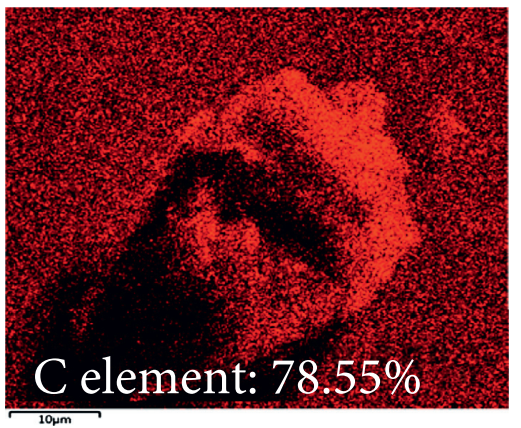

(d)

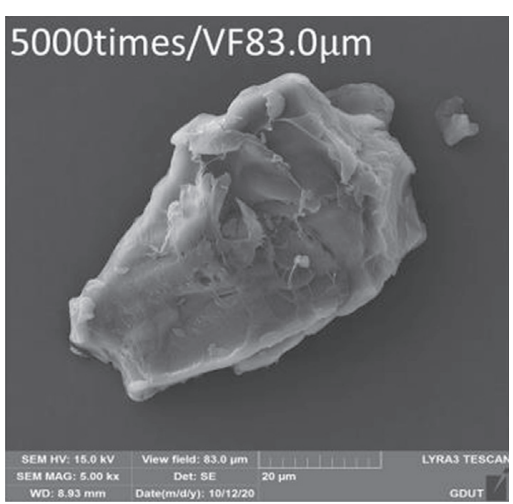

(b)

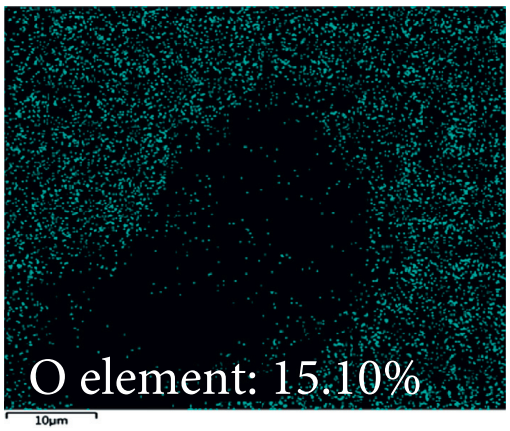

(e)

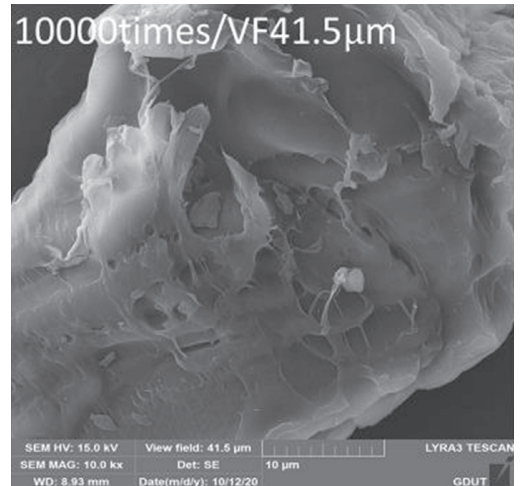

(c)

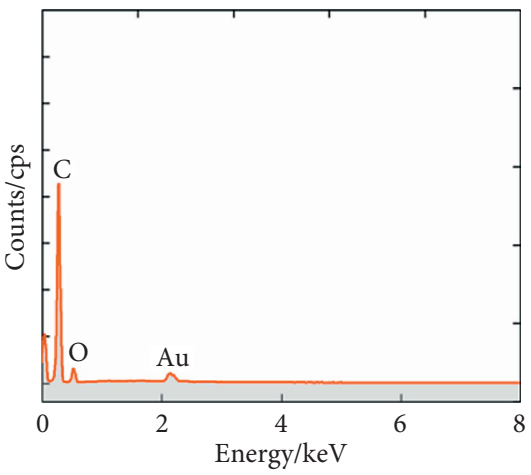

(f)

FIGURE 2: SEM/EDS testing results of the PA6 modifier.

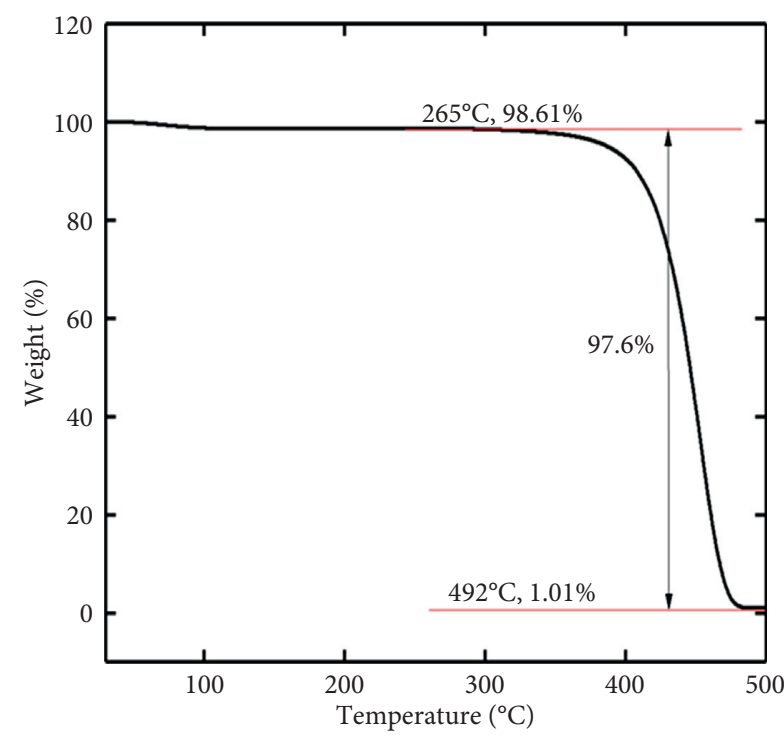

(a)

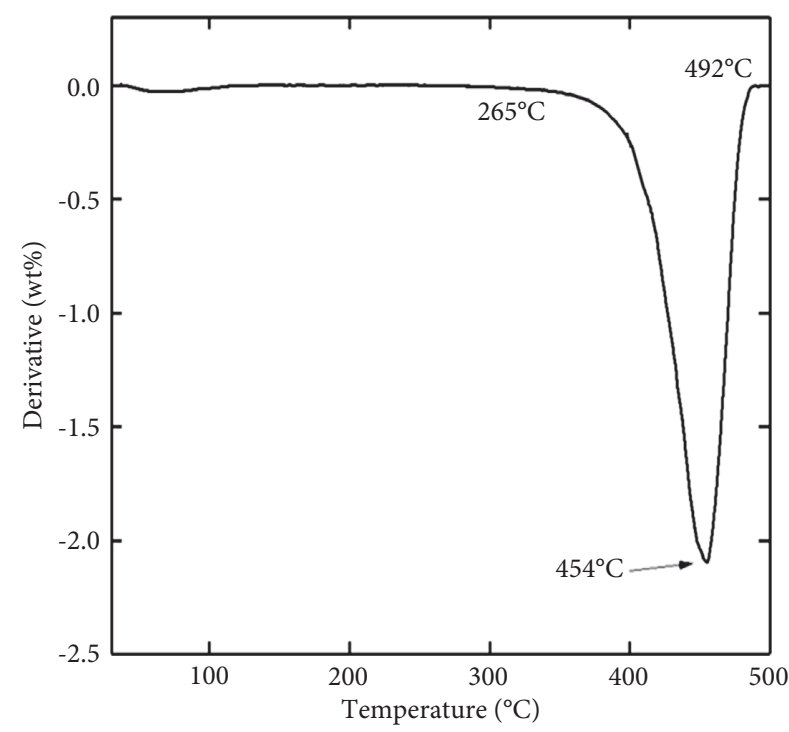

(b)

Figure 3: TG testing results of the PA6 modifier.

intensity of the curve on the spectrum became smaller and the position of the characteristic peak was almost the same as the position of the characteristic peak that appeared before, which indicated that the reaction product no longer changed.

\subsection{Physical and Viscoelastic Property of PA-Modified Asphalt}

3.2.1. Physical Property. It could be analyzed from the analysis in Figure 6 that the addition of the PA6 modifier could reduce the penetration and significantly increased the 


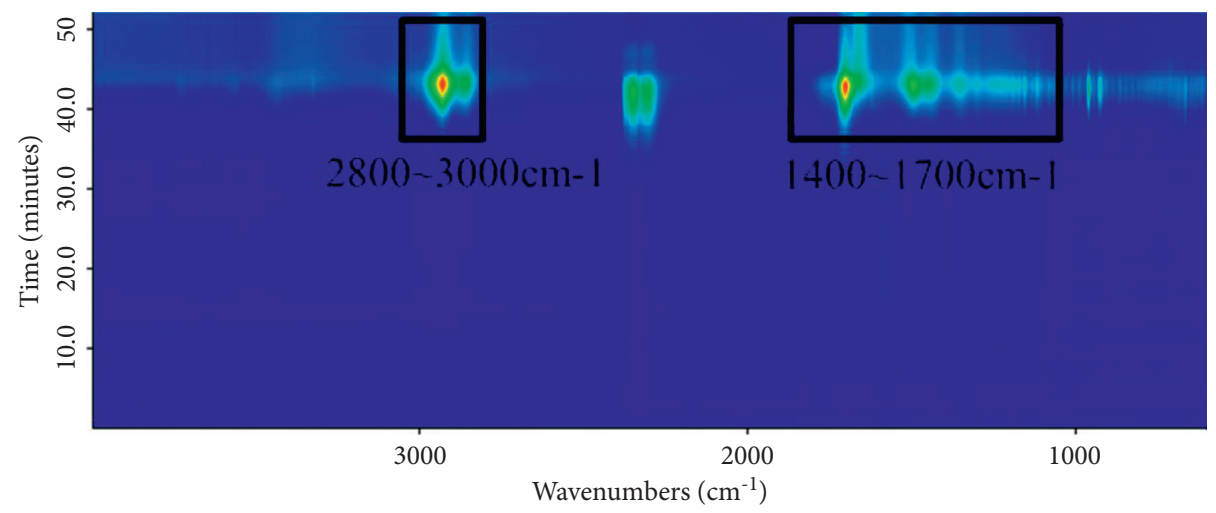

(a)

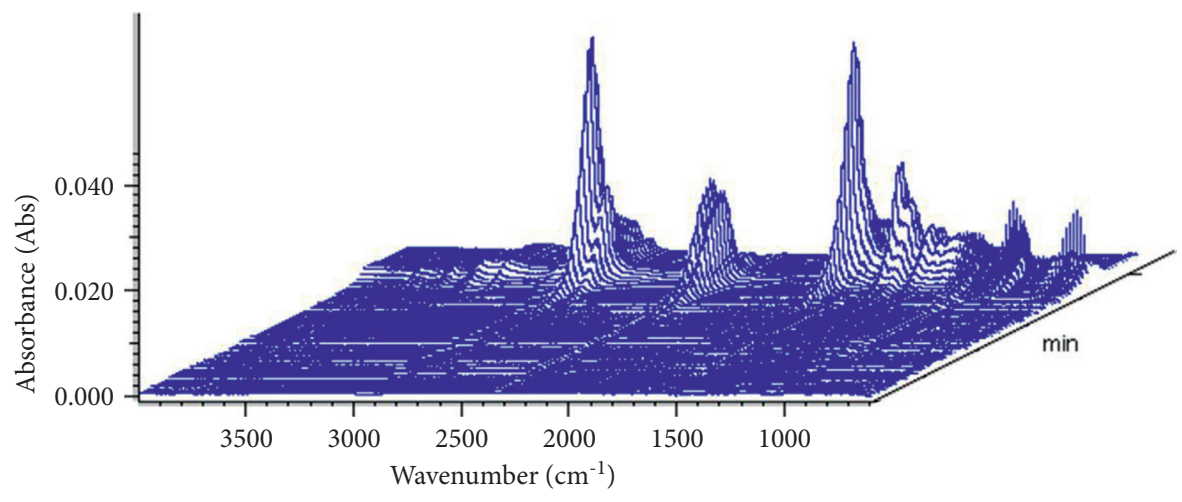

(b)

Figure 4: 2D and 3D spectrogram of the PA6 modifier.

softening point of the asphalt. When the blending amount was increased from $0.1 \%$ to $0.3 \%$, the asphalt penetration value decreased by about $13.5 \%$, which indicated that the viscosity of PA-modified asphalt was significantly improved. The corresponding results was the obvious increase in softening point, which supposed that the addition of the PA modifier improved the high-temperature stability of asphalt and has good resistance to permanent deformation under high-temperature conditions. However, the addition of the PA6 modifier would reduce the ductility of the asphalt material to a certain extent. When the amount of PA6 added was increased from $0.1 \%$ to $0.3 \%$, the $10^{\circ} \mathrm{C}$ ductility of the asphalt binder decreased by about $14.1 \%$, which indicated that the addition of PA6 would deteriorate the low-temperature crack resistance of asphalt. Therefore, the amount of the PA6 modifier should be appropriately controlled during the application process to ensure the comprehensive effect of PA6 on high-temperature performance and lowtemperature performance. The improving effect of PA6 on the thermal stability of asphalt might be achieved through change in the composition of chemical components of asphalt binder, which increased the chemical component related to the thermal stability of asphalt and increased the viscosity of asphalt material. However, the increase of asphaltene might limit the deformability of the asphalt binder when subjected to low temperature, which led to the degradation of low-temperature performance of asphalt material.
3.2.2. Brookfield Viscosity. It could be observed from Figure 7 that the PA6 modifier has the positive effect on improving the apparent viscosity of asphalt under different temperature conditions. Under the condition of $90^{\circ} \mathrm{C}$ (Figure 7(a)), with the gradual increase of the PA6 content, the apparent viscosity of the asphalt increased significantly. The addition amount was increased from $0.1 \%$ to $0.3 \%$ and the apparent viscosity of the asphalt increased by about $27.8 \%$. Compared with $70 \#$ asphalt, the increase in apparent viscosity of PA-modified asphalt could reach $34.7 \%$. Under the condition of $135^{\circ} \mathrm{C}$, the apparent viscosity of PA-modified asphalt and 70\# asphalt decreased significantly, which was mainly related to the decrease of asphalt viscosity at high temperature. Under the temperature condition of $135^{\circ} \mathrm{C}$, the apparent viscosity of PA-modified asphalt was about $25.9 \%$ higher than that of $70 \#$ asphalt and the viscosity-increasing effect was still obvious. Under the condition of $175^{\circ} \mathrm{C}$, the PA6 modifier could still increase the apparent viscosity of $70 \#$ asphalt by about $58.2 \%$, which showed that the PA6 modifier could significantly increase the viscosity of asphalt. This was consistent with the change law of the softening point and penetration of PA-modified asphalt, which suggested that the PA6 modifier had the good modification effect on the high temperature performance of asphalt.

3.2.3. LAS Test. From the LAS curve in Figures 8(a)-8(f), when the strain of PA-modified asphalt increased to $10 \%$, the stress decreased rapidly from the peak value to near the 


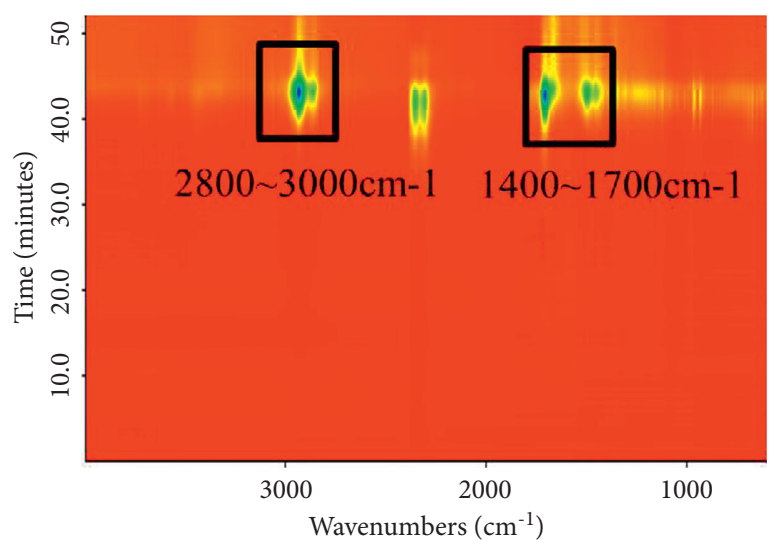

(a)

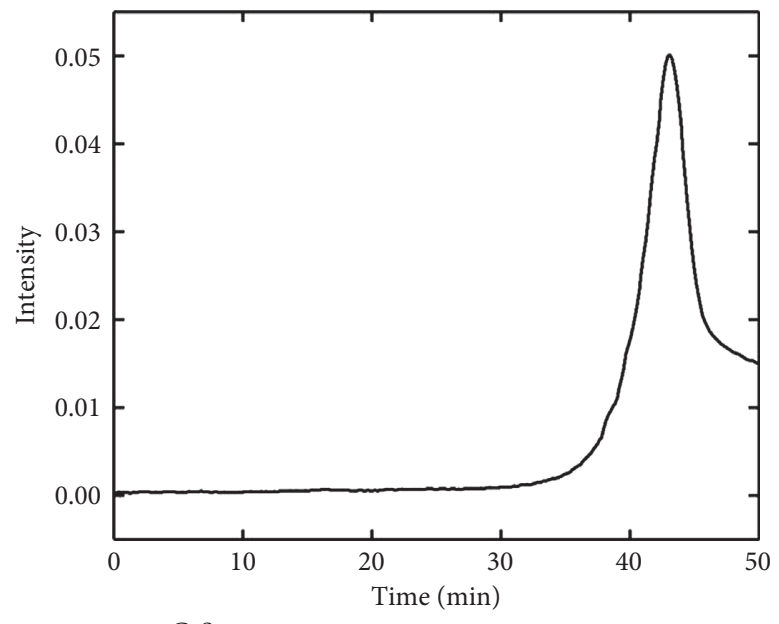

(c)

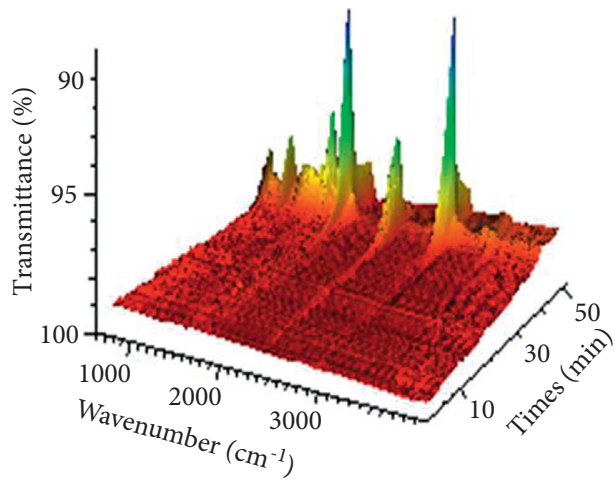

(b)

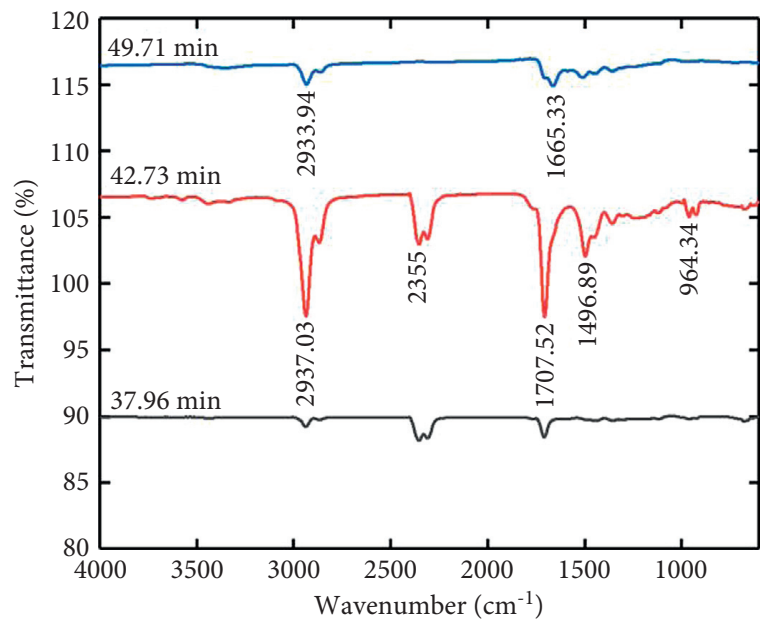

(d)

Figure 5: Dynamic FTIR testing results of the PA6 modifier.

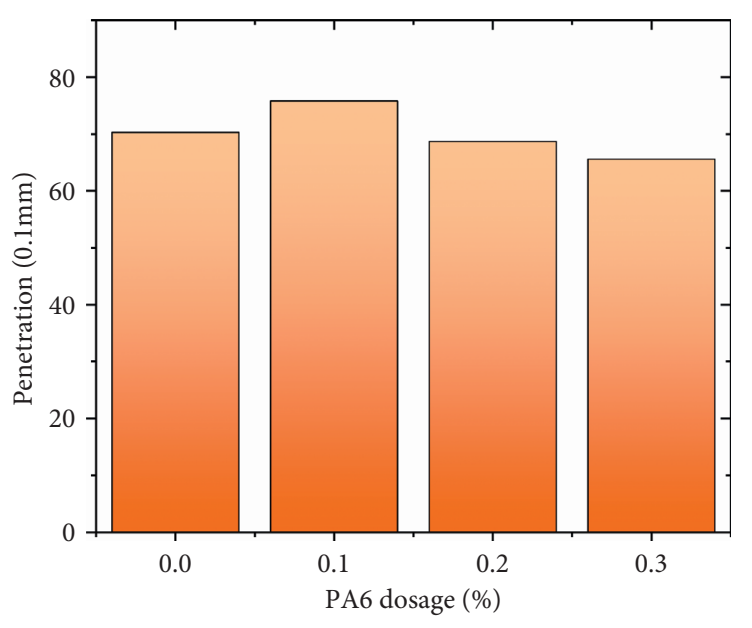

(a)

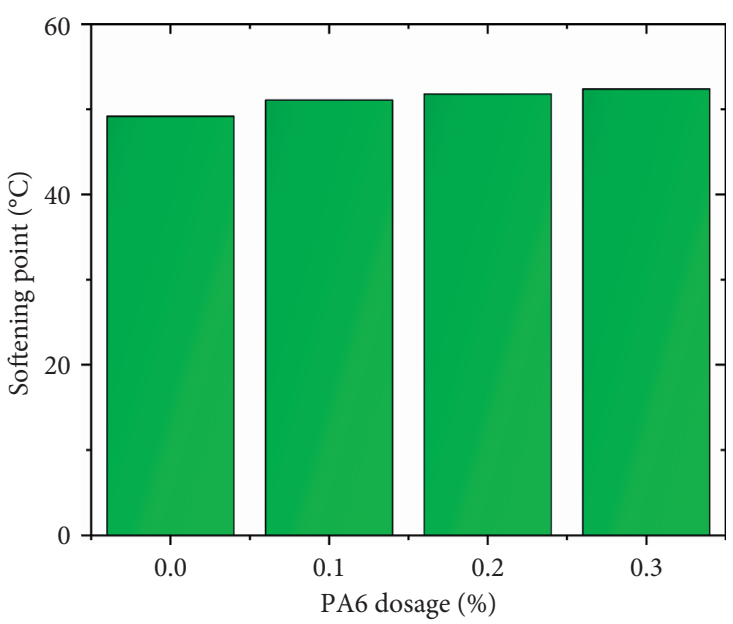

(b)

Figure 6: Continued. 


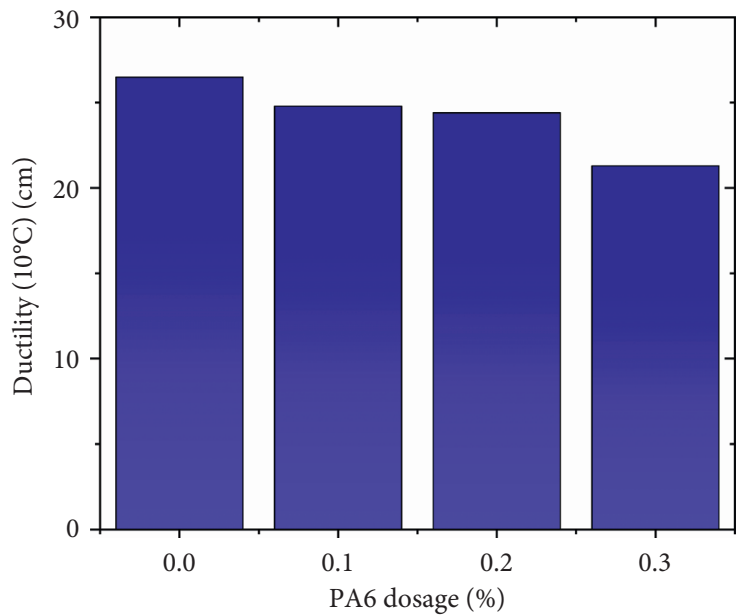

(c)

Figure 6: Physical properties of PA6-modified asphalt and 70\# asphalt.

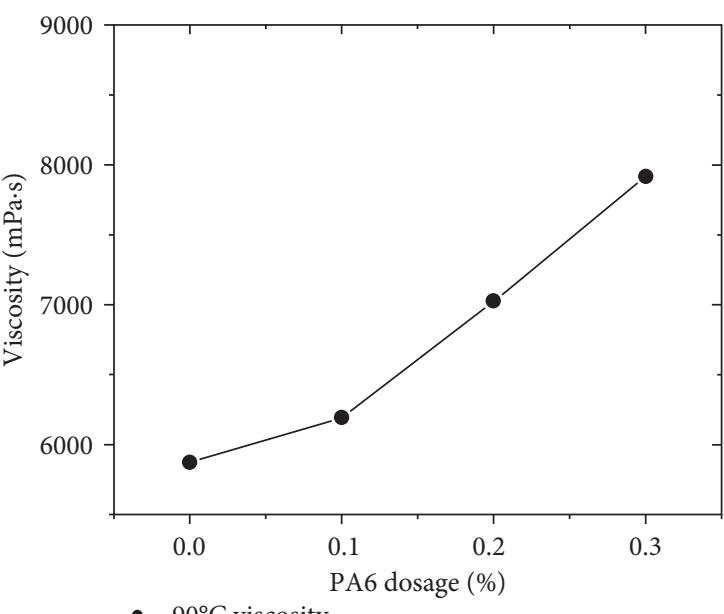

-• $90^{\circ} \mathrm{C}$ viscosity

(a)

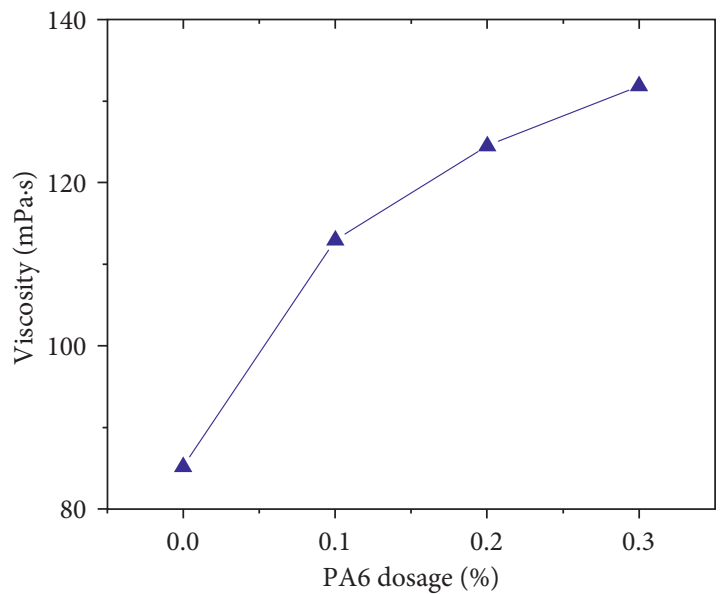

$-\mathbf{\Lambda}-175^{\circ} \mathrm{C}$ viscosity

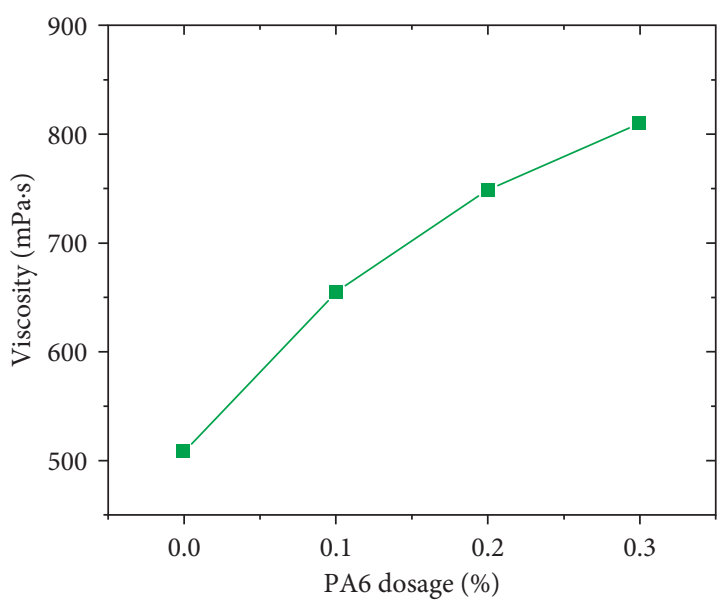

$-\square-135^{\circ} \mathrm{C}$ viscosity

(b)

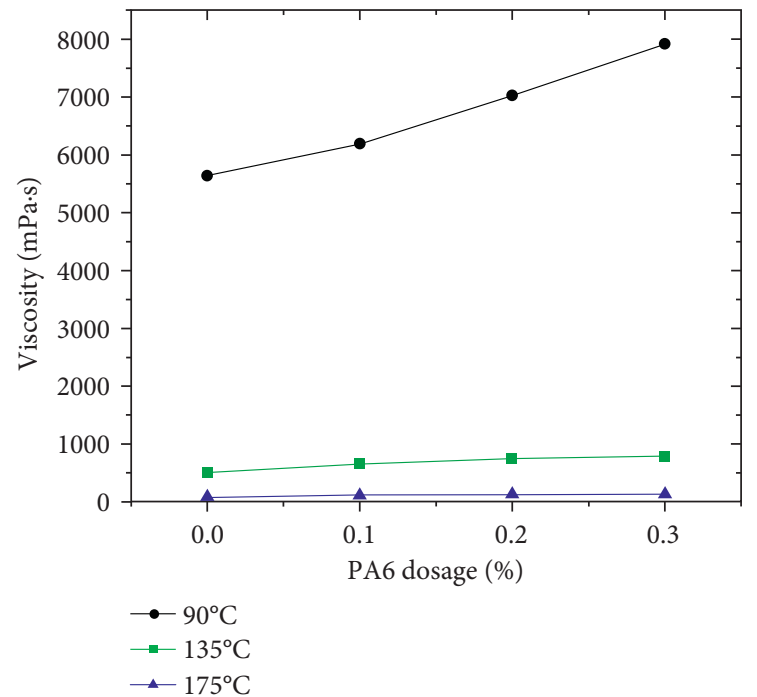

(d)

FIgURe 7: Brookfield viscosity of PA6 modified asphalt and 70\# asphalt. 


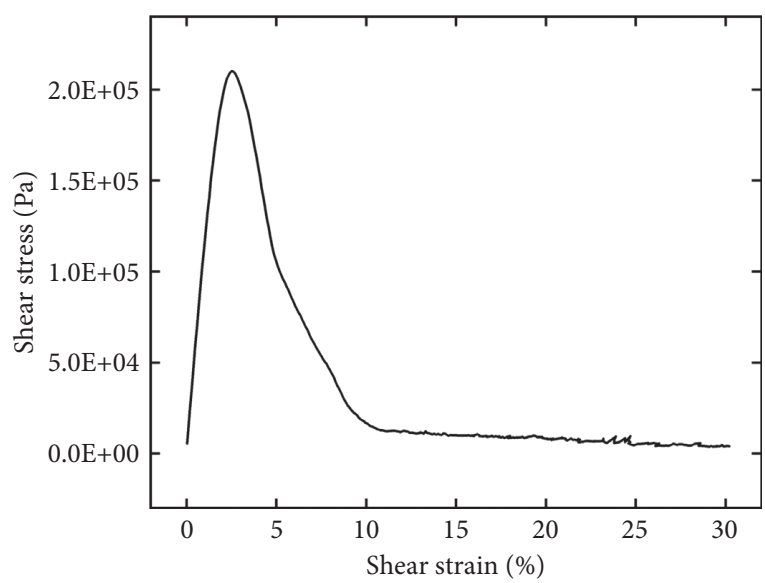

(a)

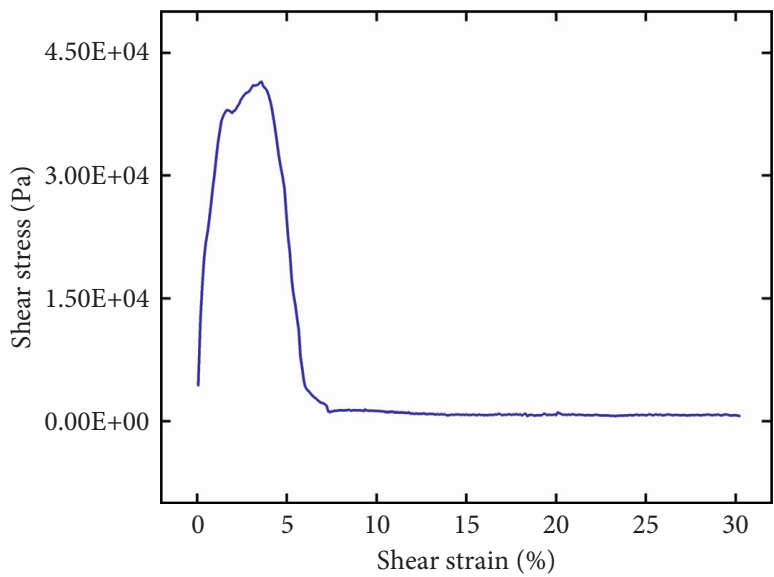

(c)

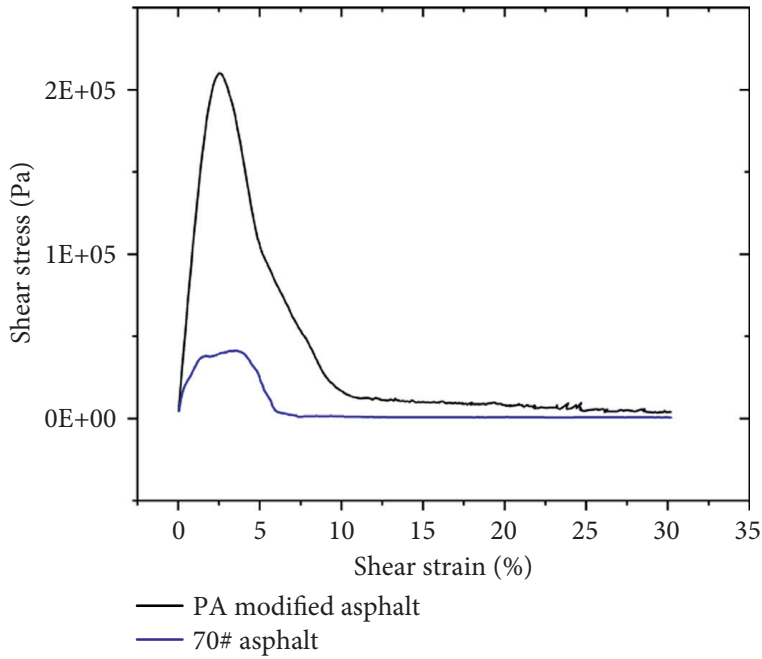

(e)

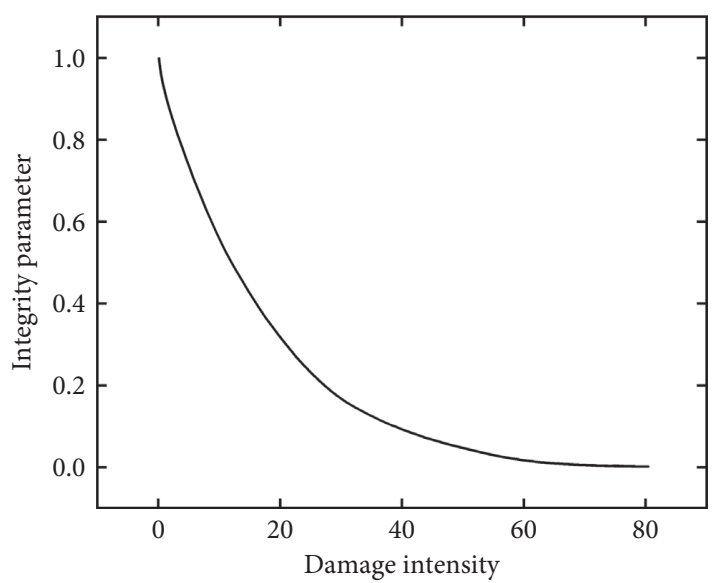

(b)

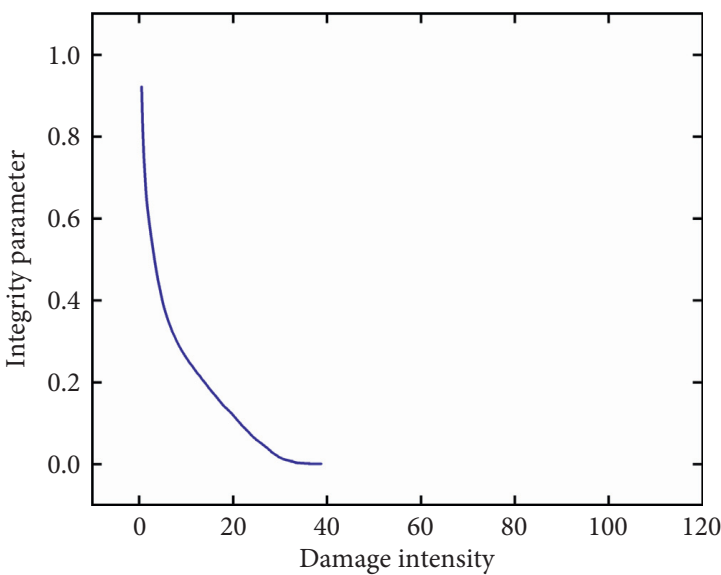

(d)

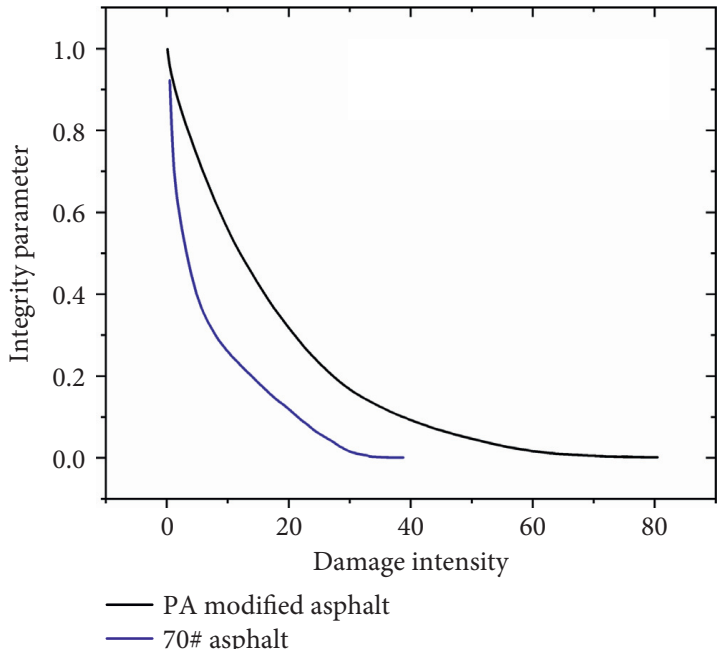

(f)

FIGURE 8: LAS analysis results of PA6-modified asphalt and 70\# asphalt.

initial value. As the strain value increased, the stress value gradually approached the zero value of the stress and the curve tended to be flat. For the 70\# asphalt, the stress peak also appeared, but the difference was that the change range of the stress-strain curve was relatively weak. The growth rate before reaching the peak was lower than that of PA- modified asphalt, and after the peak was reached, it decreased rapidly and tended to be flat. According to the LAS curves of different types of asphalt, the obtained original data were inserted into the VECD model for nonlinear fitting and the damage characteristic curves was obtained in Figures 8(b), 8(d), and $8(\mathrm{f})$, which were used as the fatigue performance failure of 
the asphalt material under the medium temperature environment as the judgment basis for the criteria. The comparison showed that the $\mathrm{C}$ value (integrity parameter) corresponding to the damage curve of PA-modified asphalt was obviously greater than that of 70\# asphalt, which supposed that the corresponding initial modulus attenuation value of PA-modified asphalt was less than 70\# asphalt under the same test conditions. At the same time, the modulus loss of PA modified asphalt was less than 70\# asphalt. When $S=20$ (Damage intensity), the $C$ value of PA6-modified asphalt was 0.02 and the initial modulus was reduced by $98 \%$, which showed that the fatigue resistance of PAmodified asphalt was better than 70\# asphalt.

\section{Conclusions}

Based on the results presented in this paper, the following conclusions could be drawn:

(1) PA6 was the semicrystalline polymer and the existence of $\gamma$ crystal form might help improving the toughness of asphalt materials effectively

(2) The thermal decomposition process of PA6-modifying agent could be divided into three stages roughly: inert weight loss stage, rapid weight loss stage, and stable stage

(3) The amount of the PA6 modifier should be appropriately controlled during the application process to promote the comprehensive effect of PA6 on hightemperature performance and low-temperature performance

(4) The $C$ value (integrity parameter) corresponding to the damage curve of PA-modified asphalt was obviously greater than that of $70 \#$ asphalt, which supposed that the corresponding initial modulus attenuation value of PA-modified asphalt was less than 70\# asphalt under the same test conditions

\section{Data Availability}

The experimental data used to support the findings of this study are available from the corresponding author upon request.

\section{Conflicts of Interest}

The authors declare that they have no conflicts of interest.

\section{Acknowledgments}

This work describes research activities mainly requested and sponsored by Guangdong Enterprise Key Laboratory for Urban Sensing, Monitoring and Early Warning (no. 2020B121202019), Science and Technology Foundation of Guangzhou Urban Planning and Design Survey Research Institute (RD no. RDI2210205046), Shanxi Transportation Holdings Group Co., Ltd. Technical Project, under Grant no. 19-JKKJ-20, Guangdong Provincial Natural Science Foundation Project, under Grant no. 2019A1515011397, and Special Fund for Science and Technology Innovation Strategy of Guangdong Province, under Grant no. pdjh2021a0149. The sponsorship and interest are gratefully acknowledged.

\section{References}

[1] X. L. Sun, J. S. Yuan, Y. K. Zhang, Y. M. Yin, J. B. Lv, and S. Jiang, "Thermal aging behavior characteristics of asphalt binder modified by nano-stabilizer based on DSR and AFM," Nanotechnology Reviews, vol. 10, no. 1, 2021.

[2] J. Jin, Y. C. Gao, Y. R. Wu et al., "Rheological and adhesion properties of nano-organic palygorskite and linear SBS on the composite modified asphalt," Powder Technology, vol. 377, 2021.

[3] T. A. Sangita, S. Khan, and D. K. Sharma, "Effect of waste polymer modifier on the properties of bituminous concrete mixes," Construction and Building Materials, vol. 25, no. 10, 2011.

[4] L. H. Lewandowski, "Polymer modification of paving asphalt binders," Rubber Chemistry and Technology, vol. 67, no. 3, pp. 447-480, 1994.

[5] B. Sengoz and G. Isikyakar, "Evaluation of the properties and microstructure of SBS and EVA polymer modified bitumen," Construction and Building Materials, vol. 22, no. 9, pp. 1897-1905, 2008.

[6] S. Pyshyev, V. Gunka, Y. Grytsenko, and M. Bratychak, "Polymer modified bitumen: review," Chemistry \& Chemical Technology, vol. 10S, no. 4, pp. 631-636, 2016.

[7] H. Y. Yu, Z. H. Zhu, Z. Leng et al., "Effect of mixing sequence on asphalt mixtures containing waste tire rubber and warm mix surfactants," Journal of Cleaner Production, vol. 246, 2020.

[8] H. N. Yu, D. Yao, G. P. Qian, J. Cai, X. B. Gong, and L. G. Cheng, "Effect of ultraviolet aging on dynamic mechanical properties of SBS modified asphalt mortar," Construction and Building Materials, vol. 281, 2021.

[9] C. O. Rossi, A. Spadafora, B. Teltayev, G. Izmailova, Y. Amerbayev, and V. Bortolotti, "Polymer modified bitumen: rheological properties and structural characterization," Colloids and Surfaces A: Physicochemical and Engineering Aspects, vol. 480, 2015.

[10] D. Y. Niu, X. W. Xie, Z. Zhang, Y. H. Niu, and Z. X. Yang, "Influence of binary waste mixtures on road performance of asphalt and asphalt mixture," Journal of Cleaner Production, vol. $298,2021$.

[11] H. L. Zhang, Z. H. Chen, G. Q. Xu, and C. J. Shi, "Physical, rheological and chemical characterization of aging behaviors of thermochromic asphalt binder," Fuel, vol. 211, 2018.

[12] R. Li, Z. Leng, P. M. N. Partl, and C. Raab, "Characterization and modelling of creep and recovery behaviour of waterborne epoxy resin modified bitumen emulsion," Materials and Structures, vol. 54, no. 1, 2021.

[13] W. He, C. Zou, Y. Pang, and X. Wang, "Environmental noise and vibration characteristics of rubber-spring floating slab track," Environmental Science and Pollution Research, vol. 11, pp. 1-19, 2020.

[14] Q. Chen, Y. Lu, C. Wang, B. Han, and H. Fu, "Effect of raw material composition on the working performance of waterborne epoxy resin for road," International Journal of Pavement Engineering, vol. 10, pp. 1-12, 2020.

[15] H. L. Zhang, C. Su, X. D. Bu, Y. P. Zhang, Y. Gao, and M. Huang, "Laboratory investigation on the properties of polyurethane/unsaturated polyester resin modified bituminous mixture," Construction and Building Materials, vol. 260, 2020. 